\title{
A Prospective, Randomized and Controlled Study on Tissue Adhesive for Skin Incision in Total Knee Arthroplasty
}

This article was published in the following Dove Press journal:

Therapeutics and Clinical Risk Management

\section{Xiangpeng Kong' \\ Minzhi Yang $\mathbb{D}^{1,2}$ \\ Renwen Guo $\mathbb{D}^{\prime}$ \\ Jiying Chen' \\ Wei Chai' \\ Yan Wang'}

'Department of Orthopaedics, Chinese PLA General Hospital, Beijing, People's Republic of China ; ${ }^{2}$ Nankai University, Tianjin, People's Republic of China
Correspondence: Wei Chai; Yan Wang Email chaiweiguanjie@sina.com; wangyanguanjie@sina.com
Background: The study focusing on the tissue adhesive in total knee arthroplasty (TKA) was rare. This study aimed to evaluate the clinical outcomes and economic costs of tissue adhesive when acting as the adjunct to standard incision closure in TKA.

Patients and Methods: From September 2019 to November 2019, we prospectively enrolled the consecutive patients who underwent simultaneous bilateral TKA in our institute. The allocation using the tissue adhesive was done after the subcuticular suture in right knee first and another method was applied in the left knee automatically. The patients' demographics, length of stay (LOS), times of dressing changes and incision-related cost, range of motion (ROM), incision-related complications and incision evaluation scores were recorded.

Results: Thirty-two patients were enrolled in this study and followed at two months after surgery. In the knees of tissue adhesive, the times of dressing change and patient scar assessment scores (PSAS) were significantly less than those standard skin closure $(\mathrm{p}=0.000 ; \mathrm{p}=0.003)$. Although there were no significant differences of the delayed discharge, incision-related cost, ROM, incision-related complications and Vancouver scar score (VSS) between two groups, $65.6 \%$ (21/32) patients preferred the tissue adhesive and only $15.6 \%$ (5/ 32) patients preferred the standard incision closure.

Conclusion: Tissue adhesive could effectively reduce postoperative wound drainage and improve patients' satisfaction rate with no difference in medical costs and ROM in TKA. The application of tissue adhesive and subcuticular sutures might be one safe and convenient method of skin closure in TKA.

Chinese Clinical Trial Registry: ChiCTR1900025730; Registered 6 September 2019.

Keywords: total knee arthroplasty, tissue adhesive, incision closure, dressing change

\section{Background}

In order to improve postoperative rehabilitation and patient satisfaction, the concept of enhanced recovery after surgery (ERAS) has gained huge attentions in joint surgery. The ideal incision closure, as an important part of ERAS, should resist some tension, promote skin healing, inconspicuous scars and less complications. ${ }^{1,2}$

At present, the standard methods of incision closure in total knee arthroplasty (TKA) are staples and sutures. ${ }^{3,4}$ However, the above methods have several obvious flaws. ${ }^{1,5}$ Firstly, the postoperative regular wound care, including disinfection and dressing changes, increased surgeons' workload and economic burden. Secondly, the residual scar has poor appearance and lowered the patient's satisfaction. Thus, the standard methods of incision closure in TKA are far from perfect. 
In recent years, tissue adhesive has been used in surgery and reported to have satisfying clinical results. ${ }^{6-11}$ 2-Octylcyanoacrylate, the main ingredients of tissue adhesive, could form a firm bond in 30 seconds when contacting the water or blood. The firm bond could cut off the wound from the outside environment and eliminate wound drainage effectively. ${ }^{12,13}$ So the tissue adhesive may be an ideal alternative to incision closure.

This prospective and self-control study aims to compare the clinical outcomes and economic costs of tissue adhesive and subcuticular suture for incision closure versus just subcuticular suture in simultaneous bilateral TKA.

\section{Patients and Methods Study Population and Design}

From September 2019 to November 2019, we prospectively enrolled the consecutive patients who underwent simultaneous bilateral TKA because of osteoarthritis (OA) in our institute. The study was approved by the local ethics committee and registered at Chinese Clinical Trial Registry. Inclusion criteria: 1) the same kind of prosthesis used in bilateral knee; 2) bilateral surgeries were performed through the anterior knee midline incision and median parapatellar approach; 3 ) the written informed consent was obtained prior to participating in this study. Exclusion criteria: 1) previous scar or suspected infection around the surgical skin; 2) keloid, psoriasis, eczema or other skin diseases; 3) allergy to the tissue adhesive; 4) underlying malignant tumors; 5) regular anticoagulation therapy; 6. peripheral vascular diseases such as venous thrombosis of lower limbs or arterial occlusion of lower limbs.

\section{Allocation and Randomization}

All patients underwent the right TKA firstly and left secondly. The knee prosthesis PS150 (DePuy, Warsaw, USA) was applied in all patients. The fixed surgical team performed the surgeries and two fixed residents performed the incision closure. Tranexamic acid (TXA, 1.0g) was given intravenously twice before exposure and incision closure. Incision closures were performed in four layers in approximately $45^{\circ}$ flexion of knee (Table 1 ).

The allocations were done after the subcuticular suture in right knee. The surgeon and the assistants remained blinded before the allocations. The method of incision closure was randomized using the computer-generated method in the opaque envelopes. One represented the
Table I Suture Material for Incision Closure in Different Layers

\begin{tabular}{|l|l|l|l|}
\hline Layer & $\begin{array}{l}\text { Tissue Adhesive } \\
\text { Group }\end{array}$ & $\begin{array}{l}\text { Control } \\
\text { Group }\end{array}$ & $\begin{array}{l}\text { Suture } \\
\text { Method }\end{array}$ \\
\hline Joint capsule & $\begin{array}{l}\text { 2-0 absorbable } \\
\text { knotless barbed suture } \\
\text { (Quill, Surgical } \\
\text { Specialties } \\
\text { Corporation, IL, USA); } \\
\text { 2-0 Ethibond non- } \\
\text { absorbable suture } \\
\text { W4843 (Ethicon, } \\
\text { Somerville, NJ, USA) }\end{array}$ & $\begin{array}{l}\text { Same } \\
\text { suture } \\
\text { Interrupted } \\
\text { suture }\end{array}$ \\
\hline $\begin{array}{l}\text { Subcutaneous } \\
\text { tissue }\end{array}$ & $\begin{array}{l}\text { 4-0 coated Vicryl Plus } \\
\text { antibacterial suture } \\
\text { (Ethicon, Somerville, } \\
\text { NJ, USA) }\end{array}$ & Same & $\begin{array}{l}\text { Interrupted } \\
\text { suture }\end{array}$ \\
\hline $\begin{array}{l}\text { Subcuticular } \\
\text { tissue }\end{array}$ & $\begin{array}{l}\text { 4-0 absorbable } \\
\text { knotless barbed suture } \\
\text { (Ethicon, Somerville, } \\
\text { NJ, USA) }\end{array}$ & $\begin{array}{l}\text { Same } \\
\text { HISTOACRYL }{ }^{\circledR} \text { tissue } \\
\text { Melsungen, German) }\end{array}$ & $\begin{array}{l}\text { Continuous } \\
\text { suture }\end{array}$ \\
\hline Skin & None & - \\
\hline
\end{tabular}

tissue adhesive and two represented the standard skin closure. The left knee automatically entered another group (Figure 1).

Two fixed residents applied the tissue adhesive evenly on the skin surface and waited for 30 seconds before employing the sterile dressing. During the hospital stay, the patients would have dressing change if any blood or exudate soaked the dressing. All patients received antibiotics within 24 hours and aspirin in postoperative 14 days. In our institute, the discharge guideline for simultaneous bilateral TKA is four days after surgery if there was no wound drainage. The wounds in all patients were under strict observation and had no special intervention after discharge.

\section{Sample Size Calculation}

According to the previous study and our preliminary results, we set $\alpha=0.05, \beta=0.10$, the mean difference of dressing change was 1.0. Estimated 24 patients would be needed to provide $90 \%$ power. ${ }^{14}$ Finally, we decided to enroll 30 patients, which allowed for $20 \%$ loss to follow up.

\section{Follow-Up and Incision Evaluation}

The preoperative, intraoperative and postoperative information of each patient, including age, gender, body mass 

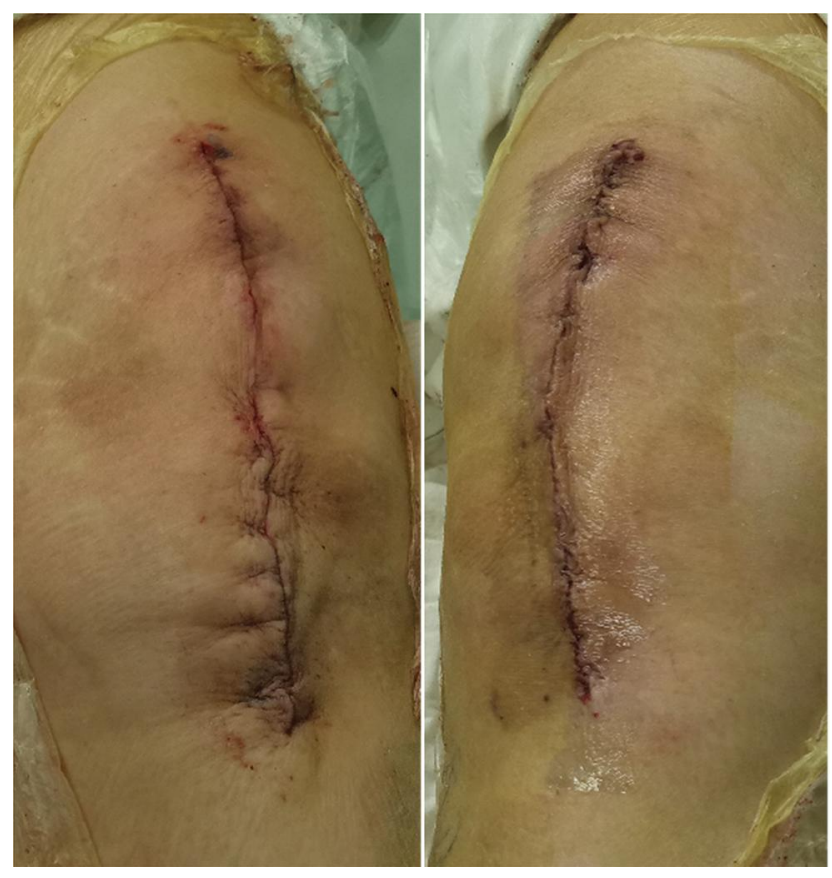

Figure I The appearances of bilateral incisions in the operating room (right: tissue adhesive group; left: control group).

index (BMI), postoperative length of stay (LOS), the times of dressing changes and the incision-related cost, were collected. Any delay in regular discharge (postoperative 4 days) due to incision was recorded.

Incision-related cost was the sum of cost of the suture, tissue adhesive, dressing, prolonging the use of antibiotics and other additional materials.

At two-month follow-up after surgery, the range of motion (ROM), incision-related complications and incision evaluation scores were recorded. ROM was measured by the electronic protractor through its two dividing rods running along the long axis of the femur and tibia. Incision-related complications were defined as redness, dehiscence, subcutaneous hematoma, delayed wound drainage ( $>4$ days). Incision evaluation scores included patient scar assessment score (PSAS) and Vancouver scar score (VSS). PSAS was evaluated by the patients themselves. ROM and VSS were always evaluated by two independent orthopedic residents (KXP and YMZ), who were unknown to which side adopted the tissue adhesive. The mean two degrees and scores evaluated by the two resident were regarded as the final scores. In addition, all patients were asked which knee of incision closure they preferred.

1. Patient scar assessment score (PSAS): the scoring system mainly refers to the patient's own feeling and the evaluation of incision. ${ }^{15}$ Six represents normal skin and sixty represents worst imaginable scar in the patient's scale (Table 2).

2. Vancouver scar score (VSS): the scoring system includes 4 items, which includes vascularity, pliability, height and pigmentation. ${ }^{16}$ On this scale, lower scores represent a more normal appearance (Table 3).

\section{Statistical Analysis}

All statistical analyses were performed by SPSS version 22 (Inc., Chicago, IL, USA). Data are showed as median, mode and interquartile range (IQR) (skewed distribution) or mean \pm standard deviation (SD) (normal distribution). Measurement data were analyzed by student's tests or rank-sum test. Count data were analyzed by rank-sum test or Fisher exact test. A value of $\alpha=0.05$ suits all tests. The intraclass correlation coefficient (ICC) was used to assess the observers' agreement: 0.81 to 1.00 , nearly perfect reliability; 0.61 to 0.80 , strong reliability; 0.41 to 0.60 , moderate reliability; 0.21 to 0.40 , fair reliability; and 0 to 0.20 , poor reliability. The inter-observer agreements of ROM and VSS were found to have nearly perfect reliability (ICC >0.81).

Table 2 Patient Scar Assessment Score (PSAS)

\begin{tabular}{|c|c|c|c|c|c|c|c|c|c|c|}
\hline$*$ & I & 2 & 3 & 4 & 5 & 6 & 7 & 8 & 9 & 10 \\
\hline $\begin{array}{l}\text { Is the scar painful? } \\
\text { Is the scar itching? } \\
\text { \# } \\
\text { Is the color of the } \\
\text { scar different? } \\
\text { Is the scar more stiff? } \\
\text { Is the thickness of the } \\
\text { scar different? } \\
\text { Is the scar irregular? }\end{array}$ & 1 & 2 & 3 & 4 & 5 & 6 & 7 & 8 & 9 & 10 \\
\hline
\end{tabular}

Notes: *0 means "no, no complains", 10 means "yes, more imaginable". "0 means "no, as normal skin", 10 means "yes, very different".

Table 3 Vancouver Scar Score (VSS)

\begin{tabular}{|l|l|l|l|l|}
\hline Score & Vascularity & Pliability & Height & Pigmentation \\
\hline 0 & Normal & Normal & Flat & Normal \\
I & Pink & Supple & $<2 \mathrm{~mm}$ & Hypopigmentation \\
2 & Red & Yielding & $2-4 \mathrm{~mm}$ & Mixed \\
3 & Purple & Firm & $>4 \mathrm{~mm}$ & Hyperpigmentation \\
4 & - & Banding & - & - \\
\hline
\end{tabular}




\section{Results}

Forty-one patients met the inclusion and exclusion criteria, and six patients declined to participate in the clinical trial. Three patients failed to complete the regular two-month follow-up and one patient underwent knee revision because of periprosthetic femoral fracture on the postoperative 10th day. Finally, the remaining thirty-two patients were enrolled in this study (Figure 2).

Among the remaining 32 patients, 62.5\% (20/32) patients were female. The median age was 58 years and the mean postoperative LOS was 4 days (Table 4 ). In the knees of tissue adhesive, the times of dressing change and PSAS were significantly less than those standard skin closure $(\mathrm{p}=0.000$; $\mathrm{p}=0.003$ ). There were no significant differences of the incision-related costs, incision-related complications, VSS, delayed discharge and ROM between two groups (Table 5).

In the knees of tissue adhesive, one patient with delayed wound drainage received pressurized dressing and prolonged use of antibiotics. In the knees of standard incision closure, four patients occur delayed wound drainage. The mean BMI was $26.10 \mathrm{~kg} / \mathrm{m}^{2}$ and no diabetes was found in these five patients. Three of them received pressurized dressing and prolonged use of antibiotics for 1 month. One of them received re-suture and prolonged use of antibiotics for 1 month. All these five patients' incision healed well before discharge. There was no periprosthetic joint infection or other incision-related complications in this cohort.

Finally, $65.6 \%(21 / 32)$ patients preferred the tissue adhesive and only $15.6 \%(5 / 32)$ patients preferred the standard incision closure (Figure 3 ).

The appearances of incisions in simultaneous bilateral TKA at postoperative two month showed in Figure 4.

\section{Discussion}

Tissue adhesive is one kind of sterile glue that exists in liquid form. Its chemical composition (2-octylcyanoacrylate) could rapidly polymerize in contact with hydroxyl ions of the blood and water. The resultant polymer is biodegradable within about ten days and bacteriostatic to gram-positive bacteria. ${ }^{9}$

Incision closure can be a key factor in early rehabilitation of TKA. Skin sutures and staples have proven to have satisfying safety in clinical practice. ${ }^{4,8}$ However, the advent of ERAS promotes earlier rehabilitation and less hospital stays following TKA, which draws two additional demanding for incision closure. One had more cosmetic

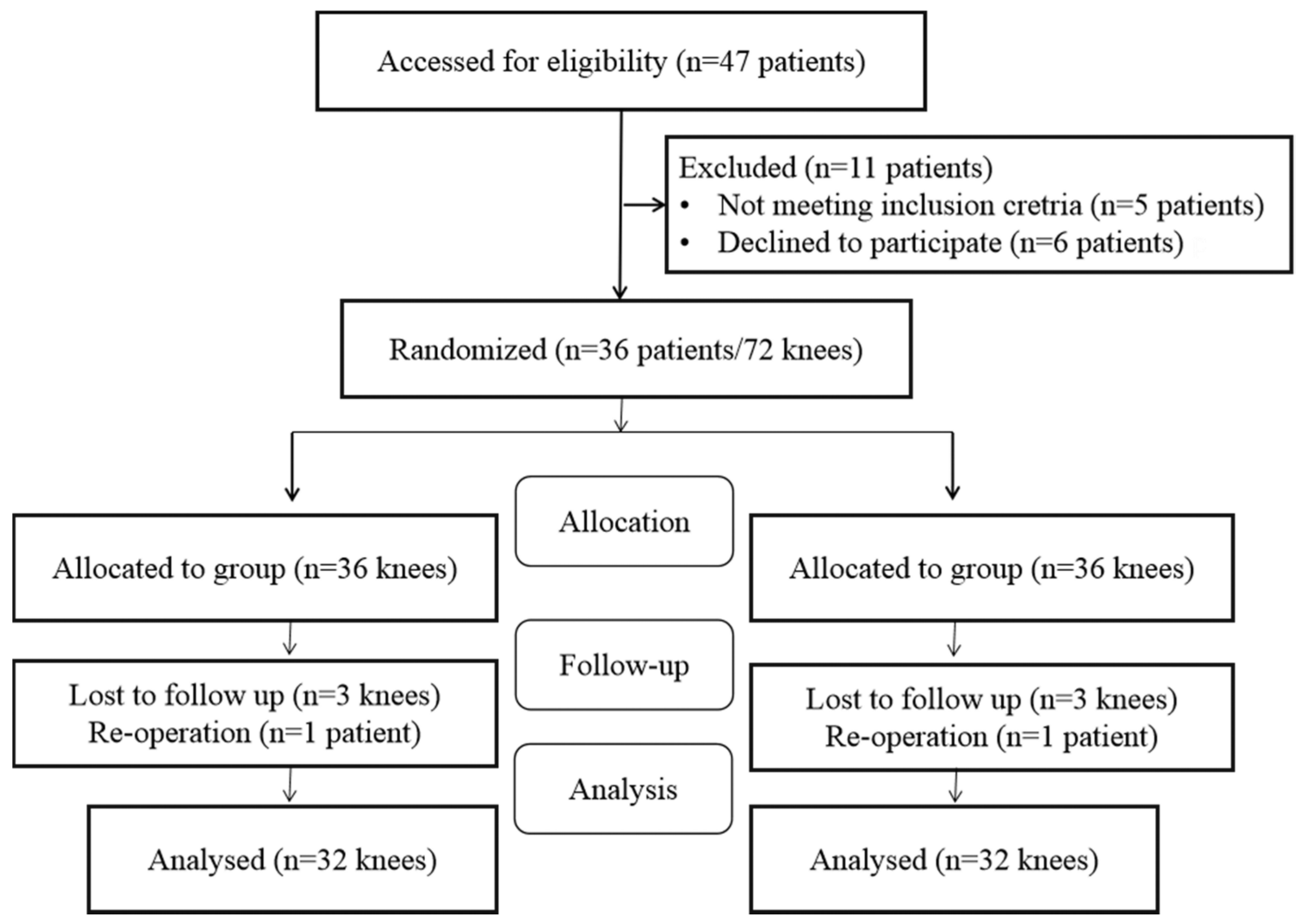

Figure 2 Flow chart of patient enrollment in this prospective study. 
Table 4 The Demographic Data in the Thirty-Two Patients

\begin{tabular}{|l|l|}
\hline Demographics & Data \\
\hline Age (median, IQR) (years) & 58,7 \\
Male: Female & $12: 20$ \\
BMI (mean $\pm \mathrm{SD})\left(\mathrm{kg} / \mathrm{m}^{2}\right)$ & $26.34 \pm 3.1 \mathrm{I}(2 \mathrm{I} .30-32.62)$ \\
ASA grade ( I : II) & $2: 30$ \\
Postoperative LOS (mean, IQR) (days) & $4.5,2$ \\
\hline
\end{tabular}

Abbreviations: IQR, interquartile range; BMI, body mess index; SD, standard deviation; LOS, length of stay.

Table 5 Comparisons of Closure Time, Dressing Change, Pain, Incision Evaluation Scores and Complications Between Two Groups

\begin{tabular}{|l|l|l|l|}
\hline Evaluation Index & $\begin{array}{l}\text { Tissue } \\
\text { Adhesive } \\
\text { Group }\end{array}$ & $\begin{array}{l}\text { Standard Skin } \\
\text { Closure Group }\end{array}$ & $\mathbf{P}$ \\
\hline $\begin{array}{l}\text { Dressing change } \\
\text { (median, IQR) }\end{array}$ & 1,0 & $2.5,2$ & 0.000 \\
Incision-related costs & 242.39 & $221.83 \pm 13.55$ & 0.423 \\
(mean \pm SD) (US dollar) & \pm 10.12 & & 0.355 \\
Incision-related & $1 / 31$ & $4 / 28$ & 0.003 \\
complications & $22.83 \pm 9.48$ & $30.57 \pm 9.54$ & 0.737 \\
PSAS (mean $\pm S D)$ & $5.13 \pm 1.16$ & $5.77 \pm 1.16$ & 0.355 \\
VSS (mean $\pm S D)$ & $1 / 31$ & $4 / 28$ & 0.183 \\
Delayed discharge & $99.19 \pm 8.12$ & $100.48 \pm 7.93$ & \\
ROM ( ${ }^{\circ}$, mean $\left.\pm S D\right)$ & &
\end{tabular}

Abbreviations: IQR, interquartile range; SD, standard deviation; PSAS, patient scar assessment score; VSS, Vancouver scar score; ROM, range of motion.

appearance, another one needed less incision care, including regular disinfectant and removal of sutures or staples.

To cater to fast rehabilitation and cosmetic need, some surgeons introduced the tissue adhesive in orthopedic surgeries. ${ }^{17-19}$ But the clinical study on the comparison with subcuticular suture in joint surgery was rare. ${ }^{10,20-22}$

Roumeliotis and Graham reported that tissue adhesive with subcuticular suture application was a viable option for skin closure after lower limb arthroplasty and can reduce the incidence of prolonged wound discharge. ${ }^{23}$ However, their study had several obvious limitations. Firstly, the study was retrospective and two groups of patients came from different time periods. Secondly, the incidence and duration of prolonged wound exudate were extracted from the medical records, but the bias in the subjectivity and reliability of medical record cannot be controlled properly. Thirdly, the study enrolled the patients undergoing total hip or knee arthroplasty and TKA accounted for only a third.

In another similar randomized and self-controlled study, Gromov et al enrolled 29 patients undergoing simultaneous bilateral TKA. ${ }^{14}$ They found that tissue adhesive plus skin staples could reduce the number of dressing changes after surgery, but not change the appearance or healing of the wound at postoperative 3 weeks. Their study only analyzed the wound drainage during the first postoperative 72 hours and did not compared the medical costs and satisfaction rate between two groups.

Although some surgeons have successfully applied the tissue adhesive in TKA, it is still too reckless to completely replace skin sutures or staples by tissue adhesive for skin closure. One prospective randomized and controlled clinical trial compared 2-octylcyanoacrylate, subcuticular suture and skin staples for skin closure following hip and knee replacement. They found that OCA was associated with less wound discharge in the first 24 hours for both the hip and the knee. However, with total knee replacement there was a trend for a more prolonged wound discharge with OCA. There was no significant difference in the length of stay in hospital, Hollander wound evaluation score or patient satisfaction between the groups at six weeks for either hips or knees. ${ }^{7}$ So we adopted the tissue adhesive as the supplement to, not substitute for subcuticular closure in this study.

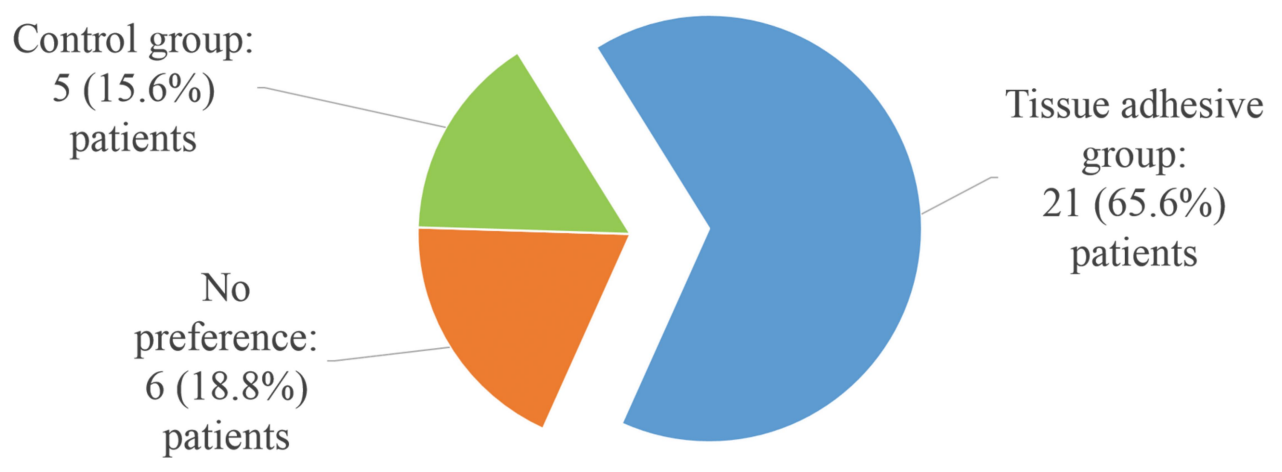

Figure 3 The preference distribution for incision closure in the thirty-two patients. 


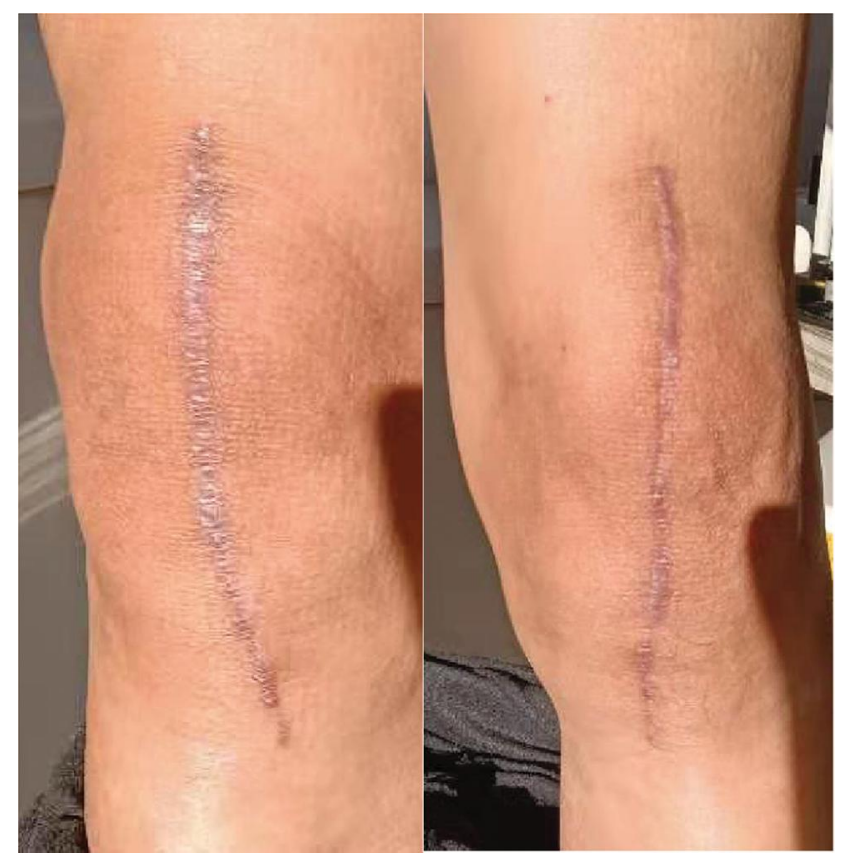

Figure 4 The appearances of bilateral incisions at postoperative two month (right: tissue adhesive group; left: control group).

This was the first study on comparing the clinical outcome, medical cost and patient preference of tissue adhesive plus subcuticular sutures with just subcuticular sutures in simultaneous bilateral TKA. The prospective and self-controlled clinical trial has eliminated the patients' personalized characteristics, such as BMI, individual healing abilities and systemic disease.

In this study, we found that tissue adhesive combining with subcuticular sutures could effectively reduce postoperative wound drainage with the similar medical cost and ROM in TKA. The MCID in PSAS showed that the differences between two groups had clinical significance. The application of tissue adhesive and subcuticular sutures might be a safe and convenient method of skin closure for fast-recovery TKA.

Although the mere subcuticular sutures could provide the patients with superior cosmetic appearance and enough resistance to skin tension during knee flexion, it still left the problem of incision drainage unresolved. ${ }^{24-26}$ In this study, just the application of subcuticular sutures in TKA was more likely to be the dragging reason of delayed discharge, especially in obese patients. Prolonged fat liquefaction or aseptic exudation could form a flow channel, where microorganisms can cause superficial or even deep infections. The tissue adhesive could isolate the internal incision and prevent the outside microorganisms from invading through the unhealed incision. Several studies also approved this view. As El-Gazzar and Gromov et al reported, when the tissue adhesive worked as an adjunct to skin staples after TKA, it could decrease postoperative wound drainage. ${ }^{11,14}$ Easier care of incision and fewer need of physicians could facilitate the patients' early daily life greatly. The patients can go straight home from the hospital without having to go to the rehabilitation institute or clinic just for incision observation. With the similar medical costs during the hospital stay, patients preferred the combination of tissue adhesive and subcuticular suture than standard skin closure. If the incisionrelated costs after discharge were took into consideration, perhaps the additional material cost of the tissue adhesive would be offset or even exceed. The use of tissue adhesive could increase the patients' satisfaction and confidence in surgery, which was also found in other studies. ${ }^{10,27}$

The risk of allergy to tissue adhesive cannot be ignored, while we did not find any allergic contact dermatitis in this cohort. Several studies reported that the rate of allergy to tissue adhesive ranged from $0.5 \%$ to $1.7 \% .^{28,29}$ Another limiting factor for tissue adhesive was the additional costs. Notice, however, that the overall costs remain unchanged or even reduced when using tissue adhesive. $^{20,21}$

The present study also had several important limitations. Firstly, the sample size and follow-up were small and short. Larger sample size and longer follow up are needed to analyze the incidence of infection and readmission. In fact, given that the prospective controlled clinical trial and incision healing period, it has already applied enough information and data. Secondly, the incision evaluation scales had subjective bias. The patients might have bias for PSAS and satisfaction due to not blind to the method of skin closure. We cannot totally blind for the closure of the second knee. The resident may meticulously tightly-closure of entire layer, when they know that the glue could not be augmented (for the second knee). Fortunately, the evaluation scores between the two observers had nearly perfect reliability. Thirdly, because the price of tissue adhesive varied in different regions and the incision-related costs after discharge were not included, the overall medical cost in this study might not applicable to other institutes. There are several products of tissue-adhesive and they need to be assessed individually. Fourthly, the patients undergoing simultaneous bilateral TKA generally have fewer medical diseases when compared with the patients undergoing unilateral TKA, which might interfere with the incision healing. 


\section{Conclusions}

Tissue adhesive could effectively reduce postoperative wound drainage and improve patients' satisfaction rate with no difference in medical costs and ROM in TKA. The application of tissue adhesive and subcuticular sutures might be a safe and convenient method of skin closure in TKA.

\section{Data Sharing Statement}

The data used and/or analyzed during the current study are available from the corresponding author (Dr CW and Dr WY) on reasonable request.

\section{Ethics}

The study was approved by the medical ethics committee of Chinese PLA General Hospital (S2019-166-01) and registered at Chinese Clinical Trial Registry (clinical trial registration number: ChiCTR1900025730; Registered 6 September 2019; http://www.chictr.org.cn/edit.aspx? $\mathrm{pid}=43067 \mathrm{andhtm}=4$ ). All procedures were conducted in compliance with the guidelines of the Declaration of Helsinki. Written informed consents of patients were obtained prior to their participation in the study.

\section{Consent for Publication}

We have obtained consent for publication.

\section{Author Contributions}

All authors made substantial contributions to conception and design, acquisition of data, or analysis and interpretation of data; took part in drafting the article or revising it critically for important intellectual content; gave final approval of the version to be published; and agree to be accountable for all aspects of the work. WC and $\mathrm{YW}$ : primarily responsible for oversight of the research project, including all data acquisition and analysis, manuscript preparation and approval. WC and $\mathrm{YW}$ were the co-corresponding authors. $\mathrm{XK}$ and MY: primarily responsible for all computational analyses in the article and the drafting of the manuscript. XK and MY were the co-first authors. RG and JC: revised the manuscript and helped perform the analysis with constructive discussions. All authors have read and approved the final submitted manuscript.

\section{Disclosure}

The authors report no conflicts of interest in this work.

\section{References}

1. Krebs VE, Elmallah RK, Anton K, et al. Wound closure techniques for total knee arthroplasty: an evidence-based review of the literature. J Arthroplasty. 2018;33(2):633-638. doi:10.1016/j.arth.2017.09.032

2. Campbell AL, Patrick DA, Barthelemy L, et al. Superficial wound closure complications with barbed sutures following knee arthroplasty. J Arthroplasty. 2014;29(5):966-969. doi:10.1016/j. arth.2013.09.045

3. Hlubek R, Walder P, Káňa J, et al. Metal staples versus conventional suture for wound closure in total knee arthroplasty. Acta Chir Orthop Traumatol Cech. 2014;81(3):233-237.

4. Kim KY, Anoushiravani AA, Long WJ, et al. A meta-analysis and systematic review evaluating skin closure after total knee arthroplasty-what is the best method? J Arthroplasty. 2017;32 (9):2920-2927. doi:10.1016/j.arth.2017.04.004

5. Eggers MD, Li F, Lionberger DR. A comparison of wound closure techniques for total knee arthroplasty. J Arthroplasty. 2011;26(8):1251-8.e1-4. doi:10.1016/j.arth.2011.02.029

6. Pelissier P, Casoli V, Le BB, et al. Internal use of n-butyl 2-cyanoacrylate (Indermil) for wound closure: an experimental study. Plast Reconstr Surg. 2001;108(6):1661-1666. doi:10.1097/ 00006534-200111000-00034

7. Khan RJK, Fick D, Yao F, et al. A comparison of three methods of wound closure following arthroplasty: a prospective, randomised, controlled trial. J Bone Joint Surg Br. 2006;88(2):238-242. doi:10.1302/0301-620X.88B2.16923

8. Donald G. 2-octylcyanoacrylate, staples, and sutures had similar wound closure outcomes after total hip or knee replacement. J Bone Joint Surg Am. 2006;88(8):1895. doi:10.2106/00004623-200608000-00041

9. Ashish K, Salim P, Vivek G, et al. Dermabond wound closure in primary hip arthroplasty. Acta Orthop Belg. 2008;74(3):349-353.

10. Miller AG, Swank ML. Dermabond efficacy in total joint arthroplasty wounds. Am J Orthop. 2010;39(10):476-478.

11. Yaser E-G, Smith DC, and Jin KS, et al. The use of Dermabond ${ }^{\circledR}$ as an adjunct to wound closure after total knee arthroplasty: examining immediate post-operative wound drainage. J Arthroplasty. 2013;28 (4):553-556. doi:10.1016/j.arth.2012.07.038

12. Nipshagen MD, Joris HJ, Beekman WH. Use of 2-octylcyanoacrylate skin adhesive (dermabond) for wound closure following reduction mammaplasty: a prospective, randomized intervention study. Plast Reconstr Surg. 2008;122(1):10-18. doi:10.1097/ PRS.0b013e318171524b

13. Bartenstein DW, Cummins DL, Rogers GS. A prospective, randomized, single-blind study comparing cyanoacrylate adhesives to sutures for wound closure in skin cancer patients. Dermatol Surg. 2017;43(11):1371-1378. doi:10.1097/DSS.0000000000001200

14. Kirill G, Anders T, Sofie R, et al. Tissue adhesive for wound closure reduces immediate postoperative wound dressing changes after primary TKA: a randomized controlled study in simultaneous bilateral TKA. Clin Orthop Relat Res. 2019.

15. Eduard R, Zloty DM. Use of a patient and observer scar assessment scale to evaluate the V-Y advancement flap for reconstruction of medial cheek defects. Dermatol Surg. 2012;38(12):1968-1974. doi:10.1111/dsu.12013

16. Baryza MJ, Baryza GA. The Vancouver scar scale: an administration tool and its interrater reliability. J Burn Care Rehabil. 1995;16 (5):535-538. doi:10.1097/00004630-199509000-00013

17. Howard BM, Eshraghi SR, Holland CM, et al. Octyl-cyanoacrylate skin adhesive is effective for wound closure in posterior spinal surgery without increased risk of wound complications. Clin Neurol Neurosurg. 2014;125:137-142. doi:10.1016/j.clineuro.2014.07.026

18. Van HC, Tailly T, Klockaerts K, et al. Sutureless circumcision using 2-Octyl cyanoacrylate results in more rapid and less painful procedures with excellent cosmetic satisfaction. J Pediatr Urol. 2015;11 (3):147.e1-5. doi:10.1016/j.jpurol.2015.02.013 
19. Olaf B, Christian F, Peter MC, et al. Cosmetic outcome of skin adhesives versus transcutaneous sutures in laparoscopic port-site wounds: a prospective randomized controlled trial. Surg Endosc. 2016;30(6):2326-2331. doi:10.1007/s00464-015-4474-5

20. Gennari R, Rotmensz N, Ballardini B, et al. A prospective, randomized, controlled clinical trial of tissue adhesive (2-octylcyanoacrylate) versus standard wound closure in breast surgery. Surgery. 2004;136 (3):593-599. doi:10.1016/j.surg.2004.02.015

21. Glennie RA, Abigail K, Douglas N, et al. MONOCRYL and DERMABOND vs staples in total hip arthroplasty performed through a lateral skin incision: a randomized controlled trial using a patient-centered assessment tool. $J$ Arthroplasty. 2017;32 (8):2431-2435. doi:10.1016/j.arth.2017.02.042

22. Nadia S, Niels-Derrek S, Johnston SS. Economic and clinical comparison of 2-octyl cyanoacrylate/polymer mesh tape with skin staples in total knee replacement. J Wound Care. 2018;27(Sup4):S12-S22. doi:10.12968/jowc.2018.27.Sup4.S12

23. Leonidas R, Mackenzie GN. Barbed suture and glue in skin closure during lower limb arthroplasty: reduced delayed discharge due to wound exudate. J Wound Care. 2019;28(11):784-789. doi:10.12968/ jowc.2019.28.11.784

24. Sanjay A, Mayank V. Concealed cosmetic closure in total knee replacement surgery - a prospective audit assessing appearance and patient satisfaction. J Clin Orthop Trauma. 2019;10(1):111-116. doi:10.1016/j.jcot.2017.11.002
25. Shuguang L, Yunmei W, Kotian RN, et al. Comparison of nonabsorbable and absorbable suture in total knee arthroplasty. Med Sci Monit. 2018;24:7563-7569. doi:10.12659/MSM.910785

26. Wyles CC, Jacobson SR, and Houdek MT, et al. The Chitranjan Ranawat Award: running subcuticular closure enables the most robust perfusion after TKA: a randomized clinical trial. Clin Orthop Relat Res. 2016;474(1):47-56. doi:10.1007/s11999-015-4209-x

27. Kavin S, Piuzzi NS, Patterson BM, et al. Skin closure with 2-octyl cyanoacrylate and polyester mesh after primary total knee arthroplasty offers superior cosmetic outcomes and patient satisfaction compared to staples: a prospective trial. Eur J Orthop Surg Traumatol. 2019.

28. Dunnett D, Caitlin P, Suzanne W, et al. Allergic contact dermatitis to dermabond (2-octyl cyanoacrylate) after total knee arthroplasty. Dermatitis. 2014;25(2):99-100. doi:10.1097/DER.0000000000000018

29. Chalmers BP, Melugin HP, Sculco PK, et al. Characterizing the diagnosis and treatment of allergic contact dermatitis to 2-octyl cyanoacrylate used for skin closure in elective orthopedic surgery. $J$ Arthroplasty. 2017;32(12):3742-3747. doi:10.1016/j.arth.2017.07.012

\section{Publish your work in this journal}

Therapeutics and Clinical Risk Management is an international, peerreviewed journal of clinical therapeutics and risk management, focusing on concise rapid reporting of clinical studies in all therapeutic areas, outcomes, safety, and programs for the effective, safe, and sustained use of medicines. This journal is indexed on PubMed Central, CAS,
EMBase, Scopus and the Elsevier Bibliographic databases. The manuscript management system is completely online and includes a very quick and fair peer-review system, which is all easy to use. Visit http://www.dovepress.com/testimonials.php to read real quotes from published authors. 